\title{
Study on Infrared PbS Detector Prepared Using Copper Electrodes of Printed Circuit Board
}

\author{
${ }^{1}$ Hariyadi Soetedjo, ${ }^{2}$ Gunawan S. Prabowo and ${ }^{3}$ Darsono Bahrun \\ ${ }^{1}$ Center for Integrated Research and Innovation and Study Program of Fisika Melins, \\ (Metrology-Electronics-Instrumentations), Universitas Ahmad Dahlan, \\ Jalan Cendana 9A, Semaki, Yogyakarta 55166, Indonesia \\ ${ }^{2}$ Center of Aerospace Technology, Lapan, Jl. Raya Lapan, Sukamulya, Rumpin, Bogor 16350, Indonesia \\ ${ }^{3}$ Ptapb Batan, Jalan Babarsari, Yogyakarta 55281, Indonesia
}

Received 2012-09-28, Revised 2013-06-05; Accepted 2013-06-11

\begin{abstract}
Copper layers of Printed Circuit Board (PCB) have been used as electrodes for PbS infrared structure detector to introduce low cost and simple in preparation. $\mathrm{PbS}$ deposition as an active layer detector has been prepared for a few micrometers in thickness using an evaporation technique under vacuum pressure at $10^{-6}$ Torr. Photoconductivity phenomenon has been observed from the measurement when IR radiation of a Tungsten lamp introduced to the detector. The sensitivity of the detector respects to the variation of radiation intensities was also observed. The results showed that the detector has good sensitivity indicated by rapid drop voltages at a short-wavelength IR region $(1-3 \mu \mathrm{m})$. This phenomenon is encouraging for further applications of detector prepared using the electrodes from a commercialized PCB.
\end{abstract}

Keywords: Infrared, Detector, Copper, Printed Circuit Board

\section{INTRODUCTION}

Infrared detectorhas become an important device in various detection system of flame and human motion, as this kind of detector has also been used in thermal imaging technologies. For a short-wavelength infrared region (1-3 $\mu \mathrm{m})$, applications could be more specific such of use of the detector in industries of steel manufacturing, mining, oil refinery and also in military. $\mathrm{PbS}$ or lead (ii) sulphide is a well-known material to be used as an active material for infrared detector, also for an interesting material of solar cell technologies. Various forms of $\mathrm{PbS}$ material have been used for a near-infrared photodetector such form of colloidal quantum dots/organic hole conductor (Im et al., 2010). In another form, $\mathrm{PbS}$ material in thin film form has been studied their IR photoconductive properties (Kotadiya et al., 2012). It's well-known that $\mathrm{PbS}$ material shows photoconductivity phenomenon when any light of a certain energy or wavelength spectrum introduced. For photoconductive device applications, $\mathrm{PbS}$ detector is widely used due to its property of very good photosensitivity in the infrared range at room temperature (Abbas et al., 2011). In the form of polycrystalline semiconductor that is considerably interesting, the detector introduces relatively low cost of production (Preetha and Remadevi, 2013). Another interesting form of nanocrystal, the $\mathrm{PbS}$ material that has a narrow band gap could have a strong quantum size for other interests (Wang et al., 2009; Chaudhuri et al., 2013; Gerasimos and Edward, 2011; Hu et al., 2013). It is a common structure for layer depositions of detector based on photoconductivity phenomenon by preparing the electrode layers to introduce sides contact with an active layer (such $\mathrm{PbS}$ ). With these contacts, the electrical current could flow from one electrode to another electrode through the $\mathrm{PbS}$ layer deposition when light introduced to the surface of $\mathrm{PbS}$ layer. Therefore, Corresponding Author: Hariyadi Soetedjo, Center for Integrated Research and Innovation and Study Program of Fisika Melins, (Metrology-Electronics-Instrumentations), Universitas Ahmad Dahlan, Jalan Cendana 9A, Semaki, Yogyakarta 55166, Indonesia 
use of the available copper layer in commercialized PCB will be an advantage to reduce the fabrication process and cost, instead of preparing the electrode layers prior to the $\mathrm{PbS}$ deposition. In this study we report a study on photoconductive phenomenon from the $\mathrm{PbS}$ detector structure prepared using the electrodes from a commercial PCB.

\section{MATERIALS AND MATHODS}

Infrared detector was prepared by depositing the semiconductor material of $\mathrm{PbS}$ on the substrate of PCB. This deposition was done by etching the pattern area of copper layer of PCB until exposing the insulating layer of fiber glass that was used by $\mathrm{PCB}$ structure as a supporter. Etching process was done to the PCB to allow the $\mathrm{PbS}$ layer deposited directly on the surface of fiber glass. The process was carried out by immersing the PCB layer with a reacted pattern into the CuSO4 solution. The unreacted surface was covered using a certain masker material as done for a common process of etching. The $\mathrm{PbS}$ material used in this experiment was

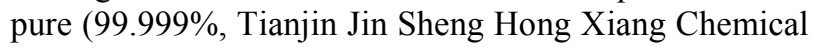
Co. Ltd.), deposited using an evaporation technique under a vacuum pressure of $10^{-6}$ Torr. The $\mathrm{PbS}$ material deposition was prepared in a few micrometers thickness. Thesupported layer of a commercialized PCB was made of a very insulating material of fiber glass. This material introduces another advantage to protect the detector from any current leakage when the substrate is not good property for insulating material. For further study of the detector performance, characterization was done through the electronic circuit prepared for a photoconductive detector as shown schematically in Fig. 1. From that figure, notations of $R_{L}, R_{d}, V_{B}$ and $V_{O}$ are load resistance, dark resistance, bias voltage and output voltage, respectively. $\mathrm{V}_{\mathrm{O}}$ could be calculated by referring to the following Equation 1:

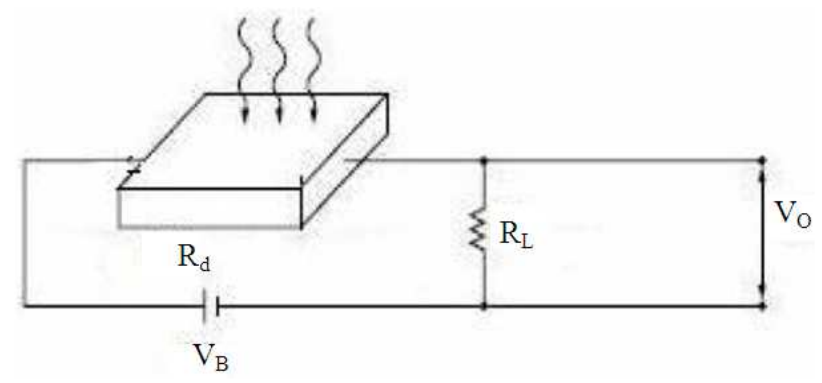

Fig. 1. Schematic diagram of a photoconductive measurement set up
$\mathrm{V}_{\mathrm{O}}=\frac{\mathrm{R}_{\mathrm{L}}}{\mathrm{R}_{\mathrm{L}}+\mathrm{R}_{\mathrm{d}}} \cdot \mathrm{V}_{\mathrm{B}}$

Measurement was done to study the photoconductivity phenomenon of the detector. For this study, the voltage bias of 1.5 volt was applied to the electrical circuit. Meanwhile, the Infrared (IR) radiation produced by Tungsten lamp (100 W) was used as an IR source. This lamp has been found able to produce the radiation wavelengths from about $1-3 \mu \mathrm{m}$ as this spectrum has been confirmed using a calibrated commercial PbS detector (P9217, Hamamatsu). The measurement was carried out under dark environment and also under light illumination at room temperature to observe the sensitivity of the detector.

\section{RESULTS AND DISCUSSION}

The detector structure was prepared using an active material of $\mathrm{PbS}$ deposited on the etched copper layer of PCB functioned as electrodes as shown in Fig. 2 (top view). From that figure, the surface of copper layer is indicated by lighter color areas, meanwhile the $\mathrm{PbS}$ deposition layer is indicated by darker color area. Use of copper electrodes of PCB is advantage because this layer could introduce a shorter process that could also reduce the process cost by referring to the standard process in a preparation of photoconductive detector structure. The standard process is usually done initially by preparing the copper or any metal layer as electrodes to the active layer deposition of detector. The $\mathrm{PbS}$ layer depositionprepared in this study is of $2.0 \times 6.0 \mathrm{~mm}$ for a few micrometers in layer thickness.

The measurement was carried out to the detector structure by varying the voltage bias to the circuit and measuring the current flow in the detector as the result is shown in Fig. 3. This measurement was done to investigate the electrical property of the layer structure. From that figure, it is observed that the curve tends linearly by variation of voltages respect to the current flow up to $4.5 \mathrm{~V}$ and then increase exponentially. Standard deviation is provided to each data point for $10 \%$. The linearity of the curve shows the Ohmic contact property of the detector structure for a certain region of voltage bias as indicated by a linear curve. The exponential curve observed for higher voltages bias shows the significant change of the detector structure for that voltage region. From the measurement, when the detector was exposed under IR radiation source for a certain power, the load resistance is also changed. 
Hariyadi Soetedjo et al. / American Journal of Applied Sciences 10 (6): 624-627, 2013

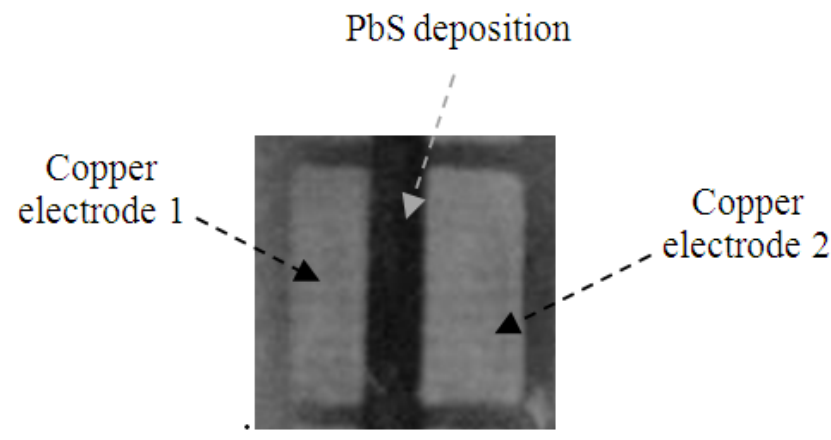

Fig. 2. Pictorial of a PbS thin film deposition using copper electrodes (top view)

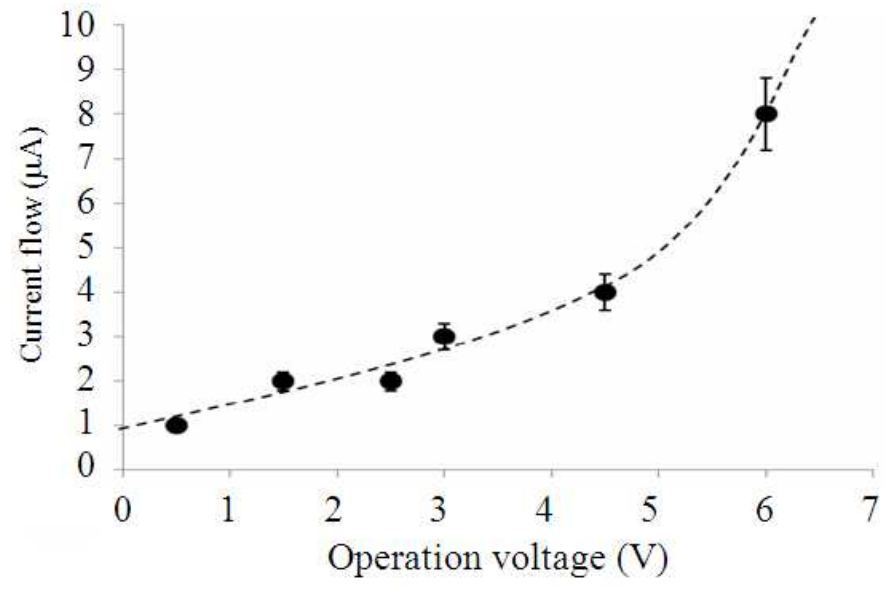

Fig. 3. A relationship between variation of voltages and output signal observed from the detector structure

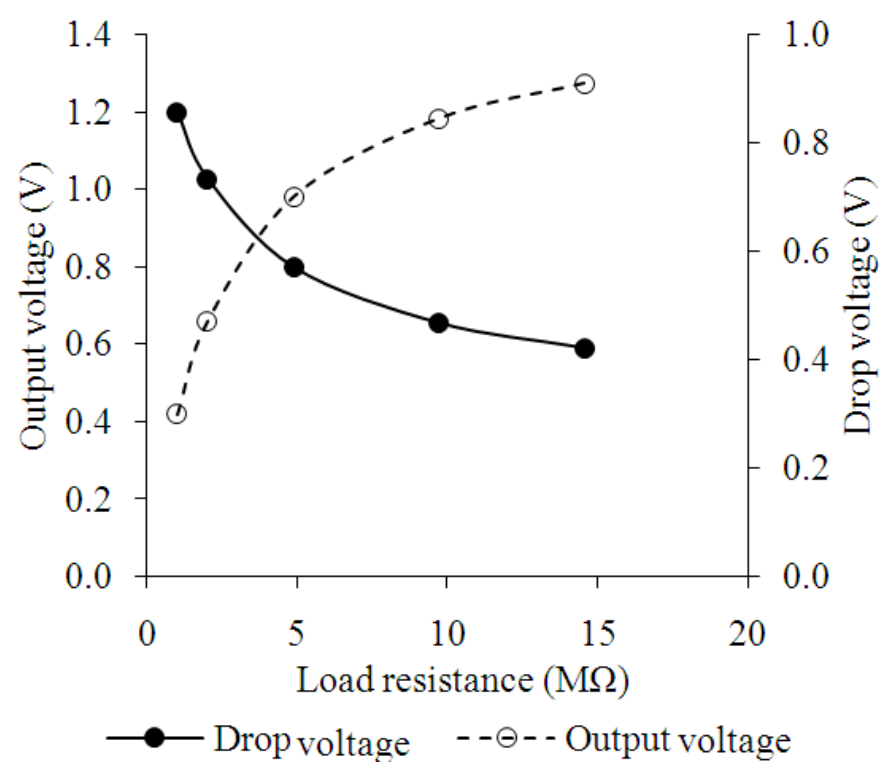

Fig. 4. Output voltages and drop voltages observed from the $\mathrm{PbS}$ detector structure 
By varying the power of lamp, the IR radiation produced is also varied. From the measurement, the increase of power will be followed by the increase of radiation as received by the detector. The measurement was done to the detector structure by introducing the IR radiation at a distance of more than $20 \mathrm{~cm}$. At the distance of less than that, the thermal effect has been observed to occur. At this condition, the load resistance was found to increase when it was exposed longer than 2 min.

Variation of load resistances respect to the change of output voltage has been measured. At a dark measurement, the dark resistance was measured of 3.4 $\mathrm{M} \Omega$. When the detector was exposed into the infrared radiation immediately, the resistance was also changed immediately to the value of $0.1 \mathrm{M} \Omega$. From the measurement, it was found that the increase of load resistance is followed by the increase of output voltage as shown in Fig. 4 (dashed curve). The curve is increased rapidly from the initial value to the resistance of $15 \mathrm{M} \Omega$. This result is then being used to calculate the drop voltage of the detector. From the calculation, the drop voltage was observed to reduce rapidly (solid curve) from $1.2 \mathrm{~V}$ to $0.6 \mathrm{~V}$ that indicates the relatively high sensitivity of the detector characteristic prepared.

\section{CONCLUSION}

By using electrode layers from commercialized $\mathrm{PCB}$, the work to prepare IR detector from $\mathrm{PbS}$ deposition has been shown more simple and introduces low cost in process. The characteristic of detector has been observed to be relatively sensitive as the drop voltage decreases rapidly by the change of light illumination indicated by the increase of load resistance. By referring to this result, further work could be improved to design infrared spectrum using other active materials of detector based photoconductivity phenomenon particularly use of any commercial PCB.

\section{ACKNOWLEDGMENT}

This study was supported by Insentif SINAS Project, Kemneg Ristek, Indonesia (Grant No.: RT-2012-0466).

\section{REFERENCES}

Abbas, M.M., A.A.M. Shehab, N.A. Hassan and A.K. Al-Samuraee, 2011. Effect of temperature and deposition time on the optical properties of chemically deposited nanostructure $\mathrm{PbS}$ thin films. Thin Solid Films, 519: 4917-4922. DOI: 10.1016/j.tsf.2011.01.053

Chaudhuri, T.K., A.J. Kothari, D. Tiwari and A. Ray, 2013. Photoconducting nanocomposite films of $\mathrm{PbS}$ nanocrystals in insulating polystyrene. Phys. Stat. Solidi, 210: 356-360. DOI: 10.1002/pssa.201228566

Gerasimos, K. and H.S. Edward, 2011. Colloidal quantum dot photodetectors. Infrared Phys. Technol., 54: 278-282. DOI: 10.1016/j.infrared.2010.12.029

Hu, C., A. Gassenq, Y. Justo, S. Yakunin and W. Heiss et al., 2013. Short-wave infrared colloidal quantum dot photodetectors on silicon. Proceedings of SPIEThe International Society for Optical Engineering, (OE' 13), pp: 8-8. DOI: 10.1117/12.2001246

Im, S.H., J.A. Chang, S.W. Kim, S.W. Kim and S.I. Seok, 2010. Near-infrared photodetection based on $\mathrm{PbS}$ colloidal quantum dots/organic hole conductor. Org. Elect., 11: 696-699. DOI: 10.1016/j.orgel.2009.12.021

Kotadiya, N.B., A.J. Kothari, D. Tiwari and T.K. Chaudhuri, 2012. Photoconducting nanocrystalline lead sulphide thin films obtained by chemical bath deposition. Applied Phys. A: Mater. Sci. Proc., 108: 819-824. DOI: $10.1007 / \mathrm{s} 00339-012-6974-7$

Preetha, K.C. and T.L. Remadevi, 2013. Behavior of chemically deposited $\mathrm{PbS}$ thin films subjected to two different routes of post deposition annealing. Materials Sci. Semiconductor Proc., 16: 605-611. DOI: $10.1016 /$ j.mssp.2012.11.004

Wang, Z., S. Qu, X. Zeng, J. Liu and C. Zhang et al., 2009. The synthesis of MDMO-PPV capped PbS nanorods and their application in solar cells. Cur. Applied Phys., 9: 1175-1179. DOI: 10.1016/j.cap.2009.01.008 